\title{
UNA CARTOGRAFÍA DE ESCRITORAS ARGENTINAS JUDÍAS DE FINALES DEL SIGLO XX
}

\author{
María del Mar López-Cabrales ${ }^{1}$
}

\begin{abstract}
Resumén: Partiendo de la concepción de que las escritoras argentinas judías presentan otra cara de la realidad y dan voz a los silenciados en la historia oficial, este ensayo analiza los discursos de marginalización emitidos por sus obras a finales del siglo XX para ver de qué manera estos modifican o no la versión oficial de la historia contemporánea argentina. Para alcanzar este objetivo, investigaremos obras y declaraciones de Alicia Borinsky, Liliana Heker, Sara Rosemberg, Ana María Shua y Nora Strejilevich. Entre sus temas y universos reinciden la muerte y el suicidio que desafían el universo canónico de las letras argentinas y la historia oficial que declaran los medios de comunicación y los políticos del país.
\end{abstract}

Palabras-Claves: Literatura argentina. Autoría feminina. Vozes silenciadas. Escritoras judías.

\section{UMA CARTOGRAFIA DE ESCRITORAS ARGENTINAS JUDIAS DO FIM DO SÉCULO XX}

Resumo: Com base na concepção de que as escritoras argentinas judias apresentam um outro lado da realidade e acomodam sujeitos sem voz e situações silenciadas na história oficial da Argentina, o objetivo deste ensaio é investigar os discursos de marginalização emitidos por seus textos literários do final do século XX, para ver como elas modificam ou não a versão oficial da história contemporânea da Argentina. Para isso, analisaremos alguns dos trabalhos e declarações de Alicia Borinsky, Liliana Heker, Sara Rosemberg, Ana Maria Shua e Nora Strejilevich. Entre seus principais temas estão a morte e o suicídio, que desafiam o universo canônico das letras argentinas e a história oficial que a mídia e os políticos do país declaram.

Palavras-Chave: Literatura argentina. Autoria feminina. Vozes silenciadas. Escritoras judias.

\footnotetext{
${ }^{1}$ Professor of Spanish and Latin American Literatures of Department of Languages, Literatures and Cultures at Colorado State University, Fort Collins. Editor of Confluencia. E-mail: Cabrales@ColoState.edu.
} 


\section{Introducción}

Hace años elaboré un ensayo sobre las tendencias de la narrativa argentina escrita por mujeres a finales del siglo XX y mis conclusiones al respecto se basaban en distintas ideas. ${ }^{2}$ Según las novelas analizadas en ese momento pude determinar que las escritoras de finales del siglo XX habían sobrevivido la terrible experiencia del Proceso, el cual era, desde distintos puntos de vista, un tema central en la narrativa de ese momento. Ya una de las antecesoras de estas narradoras finiseculares, Victoria Ocampo, fue encarcelada un mes en 1953, durante el gobierno peronista, y esta experiencia le dejó marcada para el resto de su vida: se vio privada de sus seres más queridos y, por primera vez, se encontró cerca de mujeres de otras clases sociales, "la solidaridad y el interés de estas mujeres la conmovieron de manera casi religiosa [...] y produjo una obra de teatro (inédita) sobre las mujeres de esta prisión" (MARTING, 1990, p. 398).

De esta manera, Ocampo se convertía en precedente de la novela testimonial de mujeres sobre la experiencia carcelaria como es el caso de Pasos bajo el agua de Alicia Kozameh o La escuelita de Alicia Partnoy. Por otro lado, el humor negro, la ironía, la mezcla de lo usual con lo inusual e inesperado de los textos de Silvina Ocampo se ven repetidos en la narrativa de Ana María Shua y de Alicia Borinsky. Y la constante vuelta a la infancia y al pasado son lugares comunes en la narrativa de Liliana Heker, Sara Rosemberg y Nora Strejilevich. Otro tema en el que la mayoría de estas escritoras argentinas de final de siglo reincide es el de la muerte y el suicidio. Alfonsina Storni dialoga indirectamente con las escritoras de fin de siglo, quienes han tenido, a la vez, otras antecesoras más cercanas que trataron este tema hasta llegar al propio suicidio como Alejandra Pizarnik y Marta Lynch.

Si trazamos el mapa de escritoras argentinas de finales del siglo XX podemos percibir una gran cantidad de escritoras judías en su elenco. Gorodischer explica el concepto de hermandad entre mujeres que puede ser aplicable a las escritoras argentinas en general, pero sobre todo a las judías que en sus obras presentan, por pertenecer a una comunidad doblemente

2 Véase López-Cabrales (2003). 
marginada, la otra cara de la realidad y dan cabida a los sujetos sin voz y a las situaciones silenciadas en la historia oficial argentina:

\begin{abstract}
Hay, mal que le pese a una sociedad que no puede dejar de lado la marca del patriarcado, una hermandad de las mujeres que se va construyendo lentamente [...]. Una hermandad que nos cubre a todas como poncho, ruana, sarape, manta, como la tibia resolana que cantó Carlos Gardel. [...] los textos de mujeres pueden formar OTRA América Latina de fronteras abiertas a la que cualquiera pueda entrar, recorrer, cuestionar; en la que cualquiera puede buscar, y a veces encontrar, las cortinas que filtran la luz, los dulces fragantes en pailas de cobre, las cuevas de manos pintadas, la voz que ensaya en la soledad, los espejos que cubren la muerte (GORODISCHER, 1994, p. 89).
\end{abstract}

En momentos en los que la globalización impone profundos cambios en las culturas locales, en especial en las de las regiones periféricas expuestas a lo que algunos denominan neocolonialismo, está en marcha la elaboración de nuevos paradigmas de identidades. Reflexionando sobre este tema y después de apreciar que de la lista de escritoras que seleccioné en su momento había una gran mayoría de escritoras judías, me planteé profundizar en un grupo de escritoras argentinas judías ya que es relevante tener en cuenta los planteamientos que surgen desde quienes están doblemente marginadas.

Esther Gimberant González ha recopilado un estudio profundo de los textos escritos por mujeres argentinas en los $80 \mathrm{y}$ los ha dividido en tres categorías: 1) Versiones íntimas de la Historia, 2) De la simultaneidad paradójica: viajes y voces y 3) Versiones del extrañamiento y la marginalidad. En su libro sobre este tema se analizan más de cuarenta novelas de narradoras argentinas tan diversas como: Alina Diaconú, Angélica Gorodischer, Luisa Futoransky, Vlady Kociancich, Reina Roffé, Silvia Molloy, Tununa Mercado, Liliana Heer, Ana María Shua, Alicia Steimberg, Marta Mercader, Lilina Heker, Alicia Borinsky, María Rosa Lojo, Hebe Uhart, Clara Escofet, Elena Pozzi, Luisa Valenzuela, etc. En esta lista se percibe un alto número de escritoras judías ya que en Argentina, la comunidad judía ha desempeñado un papel primordial en 
el campo de las artes, la música, la pintura, el teatro, el cine y, por supuesto, en el campo de la literatura.

El propósito de este ensayo es analizar los discursos de marginalización emitidos por voces de escritoras argentinas judías a finales del siglo XX para ver de qué manera estos modifican o no la versión oficial de la historia contemporánea argentina. Y para ello, analizaré algunas de las obras y declaraciones de Alicia Borinsky, Liliana Heker, Sara Rosemberg, Ana María Shua y Nora Strejilevich. Los temas y universos presentados en las obras de estas autoras desafían el universo canónico de las letras argentinas y la historia oficial que declaran los medios de comunicación y los políticos del país.

\section{Alicia Borinsky y la estética de lo ecléctico ${ }^{3}$}

El tango, el bolero, la telenovela, las letras de la música popular argentina, el shooping, lo postizo, lo fragmentado, lo caleidoscópico, el contrapunto, el exilio, el misterio, el destierro, las intrigas, el sexo, la violencia... la historia son palabras que podrían definir la obra de esta escritora argentina tan prolífica y a quien la crítica aún no ha dado el espacio que se merece dentro de la crítica literaria argentina actual. Alicia Borinsky nació en Buenos Aires y en 1967 se marchó a la Universidad de Pittsburgh a realizar su doctorado. En la actualidad la escritora reside en Boston donde enseña en la Universidad, aunque pasa gran parte del tiempo también en Argentina.

Borinsky ha incursionado en casi todos los géneros de una manera sorprendente. En la crítica literaria ha estudiado universos que van desde EI licenciado vidriera de Cervantes hasta María Luisa Bombal, pasando por Macedonio Fernández, Jose Emilio Pacheco, Alejandra Pizarnik, José Donoso, Jean Rhys, Alberto Guirri, García Márquez y Calderón. En estos artículos sobresale la preocupación por diferentes temas como son el miedo y la pérdida, la comunicación, la traducción, la interlocución y el deseo de llegar al "otro" sin necesidad de destruirlo. Es como si Borinsky, incluso en su trabajo de crítica literaria, quisiera entablar una conversación amistosa pero crítica con su audiencia para, de una manera "desaforada" y cómica (y aquí estoy tomando la expresión del artículo de GONZÁLEZ, 1992), llegar a lo más profundo del ser.

\footnotetext{
${ }^{3}$ Véase López-Cabrales (1998) para una versión más amplia de que incluye una entrevista a la utora.
} 
En la otra orilla de su producción destacan las novelas Mina cruelque ha sido ya traducida a varios idiomas, Sueños de un seductor abandonado, recientemente publicada, y Cine continuado. También ha incursionado esta escritora en la poesía creando parámetros e imágenes inolvidables por su crudeza y su ironía. Sus poemarios publicados son: La ventrílocua y otras canciones, Mujeres tímidas y la Venus de China, La pareja desmontable y Madres alquiladas.

Borinsky reflexiona sobre las características judías de su propia obra y explica que puede verlas en la "incertidumbre con respecto a la estabilidad de la lengua materna y en los personajes femeninos que, como una lógica de la literatura picaresca, circulan en la ciudad inventada de su narrativa. Las letras de tango formulan una poética del desencanto. La impostura y la injusticia con que la sociedad se burla de los méritos y moral me parece acoger cierto aspecto de la visión de los judíos permanentemente exiliados de su origen hipotético, incómodos y a la vez instalados en los lugares en que viven" (2000, p. 412).

De su obra de creación literaria se puede decir que roza los parámetros de lo prohibido, pero al leer su obra no nos ofendemos porque todo se resuelve con una sonrisa, aunque ésta sea de dentadura postiza. Lo inaudito de su obra reside en la desfachatez con que la autora incursiona en temas "malditos" sin insultar, a pesar del desparpajo verbal con que éstos se manejan. La escritora puede estar tratando algo tan terrible como la violencia y la tortura en su novela Mina cruely salir triunfante.

Una cosa que llama mucho la atención de Borinsky son las lecturas poéticas que realiza en estos magnos congresos académicos organizados bianualmente por el Centro de Estudios Latinoamericanos de la Universidad de Pittsburgh. Las palabras de Borinsky son siempre las que despiertan más comentarios por la frontalidad irónica con la que se acerca a cosas tan íntimas y graves a la vez que despiertan en la concurrencia sus más bajas pasiones. Es como si el público allí presente viera ante sus ojos una imagen desnuda de sí mismo. Alicia Borisnky consigue deshacernos de nuestro sentido del pudor y abrir una yaga en nuestros cuerpos con sus palabras llenas de humor irónico y amargura, a veces. Sus performances en las conferencias de LASA (Latin American Studies Association) de finales de los 90 siempre fueron un 
"despelote", una carcajada al aire fresco entre tanto encorsetamiento académico.

El mismo efecto tienen sus textos para el/la que los lee. Hay una sensación de estar asistiendo al simulacro de todo. Nada es real, pero a la vez todo es histórico. Es una manera desenfadada de contar lo que sucede a nuestro alrededor sin que nos demos cuenta, en una ciudad innominada, pero a la vez veraz. Este tira y afloja, este juego con la realidad, es lo que caracteriza su obra que se mueve al compás de sones de tango, y a la vez se mira en las vidrieras de un "shooping mall". Los personajes de sus novelas y poemas son intrépidos, saltan constantemente al abismo, sin antes dejar de hacer una mueca. Como en el poema en el que la mamá le dice a la hija que no tenga miedo que "el mundo es un lugar decente", que nada malo le espera ni contamina porque han puesto su nombre al lado de los protegidos. El poema continua diciendo que no se preocupe a pesar de las calenturas en el colectivo, las caricias desconocidas, las llamadas en mitad de la noche con voces entrecortadas, los partes de guerra, los atentados, etc..., para terminar diciendo:

Del lado de la caridad está tu nombre así lo hemos prometido

Nada de esto te alcanzará

Tu inocencia es flor doble

Con egoísmo

Con piruetas

Calculando

Tu felicidad está segura

("Lo que le dijo la mamá" de La pareja desmontable).

No sólo en la poesía, sino también en la prosa se observa este ir y venir. Hay un desplazamiento constante en los personajes entre lo que tienen y lo que quieren, entre la tierra propia (la patria) y la prometida (el exilio). Como ha señalado González (1992) esto se oberva perfectamente en el juego de las parejas de personajes (las mellizas y Cristina y la Amiga) en Mina cruel (GONZÁLEZ, 1992, p. 304-306). En una parte de esta novela, a pesar de los ruegos de la mamá, que está haciéndole los rulos a la nena para que no vaya a la fiesta porque Francisco está enamorado de Cristina y, a pesar de la belleza de la nena y de la juventud, no le va hacer caso, ésta responde con un párrafo sobre las 
realciones de poder y de amor en el mundo político que sólo pueden tener un encuadre sociohistórico: La Argentina. Después de esta parrafada y a modo de contrapunto, la nena termina diciendo:

Mami, mami, mami, olvidáte de mí y seguí haciéndome los rulos que quiero ser la más linda de la fiesta. En este mundo uno entra al poder por la cama, a los hombres me los voy a comer con cuchillo y tenedor, despacio y relamiéndome; hacéme los rulos mami que quiero estar lista, de gala, envalentonada e irresistible (Borinsky, 1989, p. 56).

La tensión que caracteriza a sus personajes femeninos sobre todo se presenta siempre en relación con el amor que aparece tras la máscara de lo grotesco, lo "kitsch" y lo telenovelesco. El poema que citamos a continuación bien podría figurar entre las letras de cualquier grupo de música de boleros o ser la descripción de una telenovela o de una cación al estilo "Rata de dos patas" de Paquita la del Barrio:

Desgraciado infiel indigno te veré en cuclillas admirando mis retratos a carcajadas articularé las palabras de nuestra despedida quiero dedicarte mi venganza

cada vez que vienes cada vez que tardas cada vez que marco tu

teléfono y no te encuentro y te pienso navegando en la ciudad

en cuartos que no conozco imbricado en porvenires que me

excluyen cada vez y desde la primera me invento tu enemiga me

desvanezco nuevamente en tus brazos para atarte paralizarte

rayito de luz novio marido de mis sueños más felices.

("Ella le canta una canción de amor" de La pareja desmontable).

En suma, la obra de Alicia Borinsky se incluye en un tipo de creación con tintes desenfadados de finales del siglo XX. No es que todo valga en su obra. La autora dice que los ángeles no tienen lugar en su universo literario, ni los jaguares. Hay en su escritura un deseo constante y unas ganas de tocar el suelo 
con rebeldía y desenfreno. Su obra es contemporánea para quienes la leen porque está repleta de cotidianeidad y fuerza. La historia de hoy se muestra por medio de un guiño y de una mueca casi girondina que despierta nuestras más bajas pasiones.

\section{La historia de su país por Liliana Heker y Sara Rosemberg ${ }^{4}$}

La realidad no existe en la Argentina de los 70 y los 80 y hay que reinventarla y reescribirla porque el dolor es incontable. Esto hacen los textos de Heker y Rosemberg. Partiendo de la ficcionalización (la memoria y el dolor de una amiga de una desaparecida en El fin de la historia, y la historia colectiva contada y revivida por un guionista que hace una película sobre este período de la historia argentina en Un hilo rojo), estas dos escritoras judías logran volver a contar lo indecible.

¿Por qué se sigue contando la historia? ¿Por qué continuar repitiendo el dolor? ¿Por qué insistir en la presencia del pasado? Nora Domínguez responde a estas preguntas con una cita de Walter Benjamin (Tesis de filosofía de la historia) “[porque] ni siquiera los muertos estarán a salvo del enemigo, si éste vence" (1993). Estos textos quieren dar una versión alternativa a la historia oficial y replantear lo anteriormente prohibido, reprimido y eliminado. Roland Spiller dice que las novelas argentinas de los 80 “indagan las relaciones entre realidad social e individual, tratando de decir o bien los indescriptibles horrores de la llamada "guerra sucia" de los militares, o lo que la censura prohibió decir.

Los escritores cumplen una función crítica frente al poder corrupto. Esta función ya fue ejercida en literatura argentina por escritores que lucharon contra los caudillos de su tiempo: Esteban Echeverría, Juan Bautista Alberdi, Domingo Faustino Sarmiento y José Mármol" (SPILLER, 1993, p. 8). Esta afirmación se aplica también a los textos de los 90 de Rosemberg y Heker. La relación entre historia y creación literaria es la base de la discusión postestructuralista y postmodernista, ya que la novela histórica reconfigura un espacio estructurado por medio de la fragmentación, la elipsis, la polifonía, el diálogo directo con la persona que lee, el perspectivismo, la parodia e ironía, la alteración del tiempo y del espacio y la hibridación. Estas novelas no intentan

\footnotetext{
${ }^{4}$ Véase López-Cabrales (2003) para un análisis con más precisión.
} 
quedarse en el pasado, como forma trasnochada de reflexión, sino que quieren triunfar sobre el futuro, venciendo los fantasmas del ayer y proyectándose hacia el mañana. Porque "hablar del pasado significa iluminar el presente: decir sin nombrar, hablar elípticamente, indirectamente, un recurso para denunciar el horror del presente, de contestar a las preguntas iniciales" (CITTADINI, 1993, p. 45).

Rosemberg, en Un hilo Rojo, traza el mapa indescifrable de un guionista de cine que está recogiendo información sobre la muerte y desaparición de un grupo de guerrilleros en Argentina. La voz narrativa del guionista da cohesión al relato que es un conjunto de testimonios, voces que llegan de Catamarca, Tucumán, Patagonia, cintas de grabaciones de conocidos y familiares de los desaparecidos, y charlas con personas que tuvieron alguna relación con ellos. La unión con el “otro", el desaparecido, se produce gracias al peso del recuerdo de Julia, y sus palabras en un diario. El guionista le dice a una Julia inexistente: "Los límites se han roto y el asesinato parece natural [...]. Entre mi vida y tu vida se desteje un mapa, y a esta altura no sé si voy o si vengo. Los puntos cardinales se han perdido en una suerte de bordado superpuesto como un círculo que no se ha cerrado ni nunca se cerrará. [...] Ahora que voy a terminar el guión, me faltan ganas de poner un punto y final. [...]. Las preguntas están envejeciendo conmigo y espero que al menos ellas no me abandonen" (ROSEMBERG, 1998, p. 201-202). El título del libro es significativo ya que nos remite al miedo: “El último dibujo que Julia me mandó desde Bolivia era casi aéreo, un círculo rojo alrededor de un animal asustado, hecho con un solo trazo. Abajo, con letra muy pequeña decía: “Como un hilo rojo el miedo nos ha ido cercando"”' (ROSEMBERG, 1998, p. 114).

Un hilo rojo dialoga de manera directa con el libro de Liliana Heker, repleto de miedos y preguntas que tampoco tienen respuestas ni final. A pesar de la ironía de su título, El fin de la historia “propone una estética que cuestiona la pérdida de las ideologías centrando su relato en una víctima de la tortura bajo el terrorismo de Estado y la vida de una compañera que padece su desaparición" (ZUFFI, 1999, 145). Estrategia paralela a la de Rosemberg en Un hilo rojo, ya que la voz narrativa central huye del recuerdo de Julia, pero siempre la lleva consigo, todas las voces y los lugares le hablan de ella. En el texto de Heker, Diana Glass cuenta la historia de su compañera Leonora 
desaparecida por el recuerdo del pasado y "por el deseo de verla viva” (ZUFFI, $1999,146)$ y, a la vez, se nos presenta la experiencia de la narradora Diana en un taller literario donde se le recomienda que no busque con tanta pasión, porque puede convertirse en un personaje de ficción. Esto es lo que hace Diana con Leonora. Cuando, por fin, se produce el encuentro de la narradora y la desaparecida, ésta ha sobrevivido, pero no es quien aquélla esperaba. "La novela de Liliana Heker trabaja sobre la memoria individual y colectiva como testimonio de los años represivos y nos deja a través del recuerdo o el deseo de Diana Glass los pliegues de una historia que no cierra" (ZUFFI, 1999, p. 147) que no tiene fin, porque la labor de resistencia continuará siempre, para que quienes murieron, desaparecieron y sobrevivieron estén a salvo gracias a este tipo de escritura que recupera la historia.

\section{Una novela de misterio con mucho de verdad}

Barrios tomados, ciudades divididas, casas de recuperación, bailes de disfraces, pasiones incontables son algunos de los temas que Shua trata $\mathrm{La}$ muerte como efecto secundario. Shua ubica su texto en un tiempo y espacio indeterminados, pero sus novelas son, en el fondo, crónicas ficcionalizadas de un Buenos Aires despiadado y cruel de fin de siglo, un cambalache que no tiene nada que envidiarle al que cantara Santos Discépolo. En la contraportada del libro de Shua se dice "La muerte como efecto secundario se desarrolla en una Argentina posible, en donde todo lo que podía ir mal, fue mal: es decir, un anticipo cruel de lo que nos está pasando aquí y ahora". En este sentido, esta novela tiene algunos puntos en común con Alicia Borinsky. Ernesto Kollody, en La muerte..., le cuenta a su ex amante su viaje iniciático, hasta conseguir sacar a su padre de una casa de recuperación para que pueda morir en paz. Así convierte a su padre en un cimarrón, que llega a un lugar donde los viejos controlan sus vidas, sus horarios y sus pasiones, y donde las mujeres tienen fama de brujas. El hijo, la voz narrativa, desde este lugar, sigue escribiendo cartas a su ex amante y confiesa que siempre pretendió dejar de compartir el universo con su padre y crear un mundo nuevo: “[...] no es la muerte, sino solamente esa nueva forma del universo lo que deseo conseguir: y si para obtenerla debo llamar a la muerte habrá sido, la muerte, a penas una 
consecuencia, nada más que una reacción adversa y no deseada, un simple efecto secundario./ Voy a seguir escribiendo [...] y mis palabras serán la prueba de que ese mundo que imagino es posible y [...] de que empecé por fin, huérfano y liviano como el aire, mi verdadera vida" (SHUA, 1997, p. 235). Kollody abre un futuro que le pertenece y que comienza después de su relato de lucha.

El mundo casi fantasmagórico presentado por la autora se entrelaza con lo posible en las novelas de Ana María Shua. En este texto hay una necesidad de profundizar en los anhelos del ser humano, en las intrigas y entregas de los enigmas universales y no se adentran en problemas específicos de la mujer, ni en un diálogo entre mujeres. Sus personajes centrales no son femeninos pero la voz narrativa de Shua describe una historia marginal y, con ello, redefine la historia oficial y hegemónica de la nación argentina.

\section{Nora Strejilevich y el testimonio polifónico sobre la historia más cruel argentina ${ }^{5}$}

Una sola muerte numerosa de la escritora judía argentinacanadiense Nora Strejilevich fue el texto ganador del premio Letras de Oro 19951996 en el género novela. Es necesario debatir el género de este texto que marca diferencias y que cruza fronteras (como manifestó Jean Franco en su momento), y analizar las consecuencias de ello, ya que mi hipótesis se basa en que el género de este texto está en la encrucijada del testimonio, la canción infantil y de protesta, el documento histórico y la novela. Esta condición enriquece al libro y provoca una reacción de grata sorpresa en la persona lectora que no se ve atrapada de manera asfixiante por la lectura, como lo hacen otros textos producidos durante o como resultado de la "guerra sucia" en Argentina.

En Una sola muerte numerosa las preguntas, las investigaciones y las vivencias diseñan un texto polifónico de fuentes orales, bibliográficas, periodísticas, solicitadas, canciones, documentos, pero, sobre todo, de voces del pasado que nos hablan "hasta los codos". Ya no hay un sólo sujeto ni un sólo texto, ya no "soy, somos, el poema" (STREJILEVICH, 1997, p. 200). Las voces que se oyen deconstruyen brutalmente "las versiones tranquilizadoras que

\footnotetext{
${ }^{5}$ Para una versión más amplia véase López-Cabrales (2001).
} 
emanan de los departamentos de estado y de las democracias cauteladas" (JARA; VIDAL, 1986, p. 3) y, por ello, el testimonio es Literatura de Resistencia, como lo ha denominado Bárbara Harlow: "the subverting discourse of mainstream speaking and writing, the intentionality of regaining the real and the truth from a postmodernist con-fusing [sic] syncretic discourse which covers but does not lay bare any longer the ideological implications of the works under discussion. When everything can be used for inter interpretative enjoyment the need to understanding [of the Latin American relaity] becomes alarmingly obvious" (HARLOW en GUGELBERGER; KEARNEY, 1991, p. 11).

Partiendo de una cita de un texto de Tomás Eloy Martínez, Una sola muerte numerosa (1997) se divide en tres partes, cada una precedida por un poema que resume la idea central de dichas partes. Estos poemas nos presentan la evolución que la/s voz/ces narradoras sufrieron antes, durante y después del Proceso. En la primera parte surge el silencio y la represión que roban nombres e identidades a las personas, sumiéndolas en un laberinto de lamentos sin rostros, sin ojos, sin voz en un país sin iniciales. Todo son rejas, silencios, paredes, todo es punto y aparte. En esta parte se cuentan las historias de cientos de personas encarceladas, torturadas; además de la caída de la autora y la desaparición de su hermano, se está relatando la historia del país entero y la infancia de una generación perseguida. En la segunda parte se devuelven los nombres, pero ya no son los mismos, no les pertenecen a quienes sobrevivieron y tuvieron que sufrir el exilio (interno o externo). Nadie los reconoce, las cicatrices son intraducibles, el dolor inexplicable. El cuerpo se reclama, la identidad se difumina en un relato de exilio, incomprensión, muerte y aislamiento de familiares, horrores de la ESMA, del Mundial de fútbol y de la guerra de las Malvinas. En la tercera parte, a partir de la conciencia de una identidad fragmentada, dividida, difusa, y de la imposibilidad de recuperar el nombre, se expresa la intención de escribir, de contar, de hablar, de reinventar, la voluntad de un oficio para resistirse al olvido. Al final, en una parodia del juego infantil del "veo, veo", el texto recupera el futuro y la esperanza a través del color verde, y del coro de voces que se resisten al monólogo asesino y al vacío inyectado, porque, como dice Strejilevich, "Perdimos una versión de nosotros mismos/y nos reescribimos para sobrevivir" (1997, p. 200). 
Los diferentes géneros utilizados en Una sola muerte numerosa se basan en las fuentes consultadas por la autora que aparecen al final del libro. Hay fragmentos del documento Nunca más (1985) y uno de ellos es la declaración que la misma autora hizo a los miembros de la Comisión Nacional sobre la Desaparición de Personas: “Durante el interrogatorio pude escuchar los gritos de mi hermano Gerardo, cuya voz pude distinguir perfectamente. Además, los torturadores se refirieron a una cicatriz que ambos -mi hermano y yo - tenemos en la espalda, lo que ratificó su presencia en ese lugar" (1997, p. 44). Otra voz que se resucita de Nunca más es la de Ana María Careaga, quien describe que a una chica secuestrada le preguntaron si prefería la picana o que la violaran, prefirió la picana, y al día siguiente pidió que la violaran. Después de violarla, le hicieron repetir que no le había pasado nada, que ellos no le habían hecho nunca nada (p. 28). Siguiendo con la experiencia de las mujeres encarceladas, se oye el llanto de esta mujer a quien se llevaron y, cuando la volvieron a dejar en la celda, le preguntaron si iba a a llorar, a lo cual la presa contestó "no señor" (1997, p. 38). El dolor de los electrodos "cuando funcionaba[n] parecía que mil cristales se rompían, se astillaban en el interior de uno y se desplazaban por el cuerpo hiriéndolo todo... no podía uno ni gritar, ni gemir, ni moverse. Un temblor convulsivo que, de no estar atado, lo empujaría a una a la posición fetal (1997, p. 31).

Existen también documentos oficiales: una copia de la solicitud de beneficio de la Ley 24.043 por la que los familiares de quienes fueron encarcelados o los mismos presos políticos obtienen una retribución monetaria del gobierno, dependiendo de los días que permanecieron "entre rejas", como expresa Strejilevich. Se presentan sentencias judiciales, como la que recupera la no aprobación de la privación de libertad del primo de la escritora y se resuelve la absolución de los apresados, como si nada hubiera sucedido (que era el objetivo más claro de los militares al terminar la dictadura). Testimonios del CONADEP, como el que explica el sistema de baño semanal en las cárceles, de a 8 y de 1 minuto de duración, y de cómo, entre más de cien que eran, tenían que compartir 5 ó 6 pedazos de trapo para secarse" (1997, p. 90).

Se citan bastantes artículos de Prensa de Página 12y el fragmento del informe de La Nación, en 1985, en relación a los juicios de los generales 
Lambruschini, Agosti, Viola y Anaya, los cuales manifestaban: "Nada tengo que reprocharme, Ya me ha perdonado Dios, 29 desaparecidos figuran e las listas de sobrevivientes de los recientes terremotos en México, o nada tengo que agregar" (1997, p. 75). Estas declaraciones cierran una lista extensa de términos encadenados empleados durante el Proceso: Abatir al enemigo, Chupar, Estar en la joda, Subversivo, Tabique, Torturadores, Métodos de interrogatorio, Picana, Quirófano, Tubo, etc.

En Una sola muerte numerosa se incluye también la voz de los torturadores en el comunicado número 19 del 24 de marzo de 1976, día en el que se hace oficial el golpe de estado y se comunica a la población argentina que se permite la pena de reclusión con tiempo indeterminado a quien se relacione con o forme parte de los sectores subversivos de la sociedad (1997, p. 73). También se citan partes de distintos dossieres. En uno se describe que la Escuela de Mecánica de la Armada (uno de los lugares de torturas más conocido en el Proceso) estaba entre dos de los barrios más ricos de Buenos Aires. y que los prisioneros eran llevados a la enfermería del sótano, torturados y sacados por la puerta lateral, introducidos en un camión, llevados al Aeroparque "e introducidos en un avión que volaba hacia el sur, mar adentro, donde eran tirados vivos" (1997, p. 154).

El texto, como toda reescritura, es una constante vuelta atrás en el tiempo, a través de canciones infantiles, dichos y juegos de infancia, tangos y canciones que cantaba la mamá mientras lavaba, planchaba, concinaba, ordenaba etc. cuyas letras varíaban según el estado de ánimo, canciones de protesta y comics políticos como el de Mafalda.

Jugando con esta voz que hace referencia a una nación entera, el texto, además de recoger partes íntimas del testimonio de la autora, como algunas cartas escritas por la mamá, incluye declaraciones falsamente conciliatorias de 1994 del presidente de la nación: “las madres, pese al tiempo transcurrido, siguen incitando a la violencia, agraviando, insultado y alentando a muchos argentinos que quieren paz a que a que entren al mundo de la violencia" (1997, p. 169).

Una sola muerte numerosa posee numerosas citas literarias de escritores como Rainer María Rilke (p. 191), Juan Gelman (p. 189), Cortázar (p. 
169), Verbitsky (p. 149), Paoletti (p. 136), Pablo Conti (p. 82), Bayer (p. 53), Federico García Lorca (p. 44), y Tomás Eloy Martínez (p. 9).

Después de la libertad se suceden el miedo, el silencio, la muerte, la soledad, el olvido, el insomnio, el indulto 6 . "El silencio encierra la imposibilidad de decir eso, el horror, lo terrible" (1997, p. 133), porque mientras se vive en el terror, uno casi no es consciente: “te acostás a dormir con el terror, lo incorporás. Y cuando pasa mirás para atrás te preguntás ¿cómo pudimos haber soportado todo esto, cómo pudimos haber tolerado que te llamen a la mañana siguiente para decirte: "che, cayó fulano anoche", y vos digás "puta, ¿qué cagada", y cortés el teléfono?" (1997, p. 72).

Estas voces son parte de una voz numerosa, de una identidad que se ha querido aniquilar. Nora Strejilevich fue arrestada con su hermano el 16 de julio de 1977, en 1980 ella fue puesta en libertad y salió del país, a su hermano no volvió a verlo nunca más. En 1982 recibió asilo como refugiada política en Canadá. El texto en cuestión termina con la llegada de la autora a Buenos Aires un 24 de marzo de 1993, dieciséis años después del golpe militar. Aún la gente protesta en las calles.

Una sola muerte numerosa no cuenta la experiencia de su autora, habla por todo un país y por todos los sectores sociales oprimidos y diezmados en cualquier parte del mundo, a lo largo de la historia de la humanidad (perseguidos y encarcelados injustamente por sus ideologías de oposición al gobierno hegemónico), presos políticos, mujeres infelices, judíos, exiliados, inmigrantes, etc. Una sola muerte numerosa es una proclama, un grito a voces en contra de la violación de los derechos humanos.

\section{Conclusión}

Hemos podido ver que en los textos de Borinsky, Rosemberg, Heker, Shua y Strejilevich se cuenta la historia argentina desde distintos puntos de

\footnotetext{
${ }^{6}$ En el 93, cuando la autora regresa a Buenos Aires, se publican en Clarín las declaraciones del Presidente del Régimen instaurado en el 76, Roberto Viola, quien fue condenado a 16 años de cárcel por las graves violaciones a los derechos humanos, condena interrumpida por el indulto que le concedió el gobierno del Presidente Menen. Viola manifiesta que en los años del 'Proceso' no hubo terrorismo de Estado: la expresión de terrorismo de Estado no va y dice que el golpe fue un hecho que contó con el apoyo de prácticamente toda la sociedad argentina sin otra oposición que la del ámbito subversivo (1997, p. 195).
} 
vista. Alicia Borinsky, en un artículo sobre Alejandra Pizarnik titulado "La memoria del vacío: Una nota personal en torno a la escritura y las raíces judías", expone que:

Los judíos que llegaron a Argentina huyendo de las masacres nazis y de los progroms rusos vinieron con las lenguas de sus lugares de origen. Al idish se unía el ruso y el polaco. Y fue en ruso y en polaco que podían evocar, simultáneamente, las experiencias su juventud y el dolor de la exterminación y la humillación. [...] practicar constantemente una poética de la distancia, saber que no estaban más allá y que el acá era algo irreversiblemente extranjero, se convirtió para ellos en una realidad cotidiana (BORINSKY, 2000, p. 411).

Esta condición expresada parece verse repetida en los textos de las escritoras argentinas judías. Esta necesidad de contar con distintas "lenguas" y estrategias narrativas la realidad innombrable argentina, las experiencias de “exterminación y humillación” de una nación debastada por la historia de la represión militar a finales de los setenta y de la crisis económica actual, es algo que unifica a las narrativas comentadas. Borinsky dice que Argentina se convirtió en una "especie de esponja que absorbió a todos para transformarlos en algo que no es asimilación sino fusión cultural incómoda, con fisuras y resentimientos" (2000, p. 411). Por ello, estas voces presentan características diferentes a las del discurso oficial. Los universos presentados en las obras de estas escritoras doblemente marginadas por ser judías y mujeres se presentan como necesarios para comprender la geografía completa de un país golpeado por la incomprensión de los discursos totalizadores de la globalización y de la exclusión de quienes se expresan desde el margen.

La comunidad de escritoras judías argentinas presenta algo en común. Como comenta Borinsky: "A lo nomádico y universalizante se opone lo local con una marca histórica definida. La ambiciosa obra de Marcos Aguinis, con su simultánea exploración de la historia y del presente, universaliza y localiza al mismo tiempo. Entre los poetas, el itinerario de Luisa Futoransky y Juan Gelman es un registro de la multiplicidad de voces que emergen de esta 
pasión por dar elocuencia a una palabra prestada y apropiada por la escritura" (2000, p. 412).

Esta misma pasión y sensación de injusticia e impostura que se aprecia en las obras de Borinsky recorre los textos de las escritoras judías analizadas en este ensayo. Quizás por ello haya una relación autobiográfica entre el judaísmo y la obra de escritoras como Ana María Shua, Nora Strejilevich, Liliana Heker, Sara Rosemberg y Alicia Borinsky.

En este análisis he querido reflexionar sobre estas otras voces que hablan a gritos, que no olvidan y que fueron capaces de forjar un idioma y una cultura diferentes; quise trazar el entramado de relaciones entre una comunidad que ha ido siempre a la cabeza de las letras argentinas. Espero que con mi ensayo haya podido contribuir a la creación de una cartografía de escritoras argentinas judías de fines del siglo XX para así comprender mejor el siglo XXI.

\section{Referências}

BORINSKY, Alicia. Mina cruel. Buenos Aires: Corregidor, 1989.

BORINSKY, Alicia. La memoria del vacío: Una nota personal en torno a la escritura y las raíces judías. Revista Iberoamericana, vol. LXVI, n. 191, p. 409412, 2000.

CITTADINI, Fernando. Historia y ficción en Respiración artificial. In: SPILLER, Roland (Ed.). La novela argentina de los 80. Frankfurt: Editorial Vervuert, 1993.

DIACONÚ, Alina. Los devorados. Buenos Aires: Atlántida, 1992.

DOMÍNGUEZ, Nora. Un mapa hecho de mujeres. In: SPILLER, Roland (Ed.). La novela argentina de los 80. Frankfurt: Editorial Vervuert, 1993.

FRANCO, Jean. Marcar diferencias, cruzar fronteras. Santiago de Chile: Editorial Cuarto Propio, 1996.

GONZÁlEZ, Esther Gimberant. Aventuras del desacuerdo. Novelistas argentinas de los 80. Buenos Aires: Danilo Vergara, 1992.

GORODISCHER, Angélica (Ed.). Mujeres de palabra. Puerto Rico: Editorial de la Universidad de Puerto Rico, 1994. 
GUGELBERGER, Georg; KEARNEY, Michael. Voices for the Voiceless: Testimonial Literature in Latin America. Latin American Perspectives, v. 69, 1991.

HEKER, Liliana. El fin de la historia. Buenos Aires: Alfaguara, 1996.

JARA, René; VIDAL, Hernán. Ed. Testimonio y Literatura. Minneapolis, Minnesota: Institute for the Study of Ideologies and Literatures, 1986.

LOJO, María Roso. La Princesa Federal. Buenos Aires: Planeta, 1998.

LÓPEZ-CABRALES, María del Mar. Dentaduras postizas y pasiones ocultas en la escritura de Alcia Borinsky. Confluencia, vol. 13, n. 2, p. 171-180, 1998.

LÓPEZ-CABRALES, María del Mar. La pluma y la represión. Escritoras contemporáneas argentinas. New York: Peter Lang, 2000.

LÓPEZ-CABRALES, María del Mar. La polifonía de un texto que es muchos textos: Una sola muerte numerosa de Nora Strejilevich. Bulletin of Hispanic Studies, vol. 78, n. 2, p. 241-246, 2001.

LÓPEZ-CABRALES, María del Mar. Reincidencias e innovaciones en la narrativa argentina de mujeres de fin de siglo: los 90. In: RUIZ BARRIONUEVO, Carmen. La Literatura Iberoamericana en el 2000. Balances, Perspectivas y Prospectivas. Salamanca, Spain: Ediciones Universidad de Salamanca, 2003, p. 939-949.

MARTING, Diane. Escritoras de Hispanoamérica. Una guía biobibliográgifa. México: Siglo XXI, 1990.

ROSEMBERG, Sara. Un hilo rojo. Madrid: Espasa, 1998.

SHUA, Ana María. La muerte como efecto secundario. Buenos Aires: Editorial Sudamericana, 1997.

SPILLER, Roland (Ed.). La novela argentina de los 80. Frankfurt: Editorial Vervuert, 1993.

STREJILEVICH, Nora. Una sola muerte numerosa. Miami: Letras de Oro, 1997.

VIDAL, Hernán. Fascismo y literatura: Reflexiones para una recanonización. Mineápolis: I\&I, 1985.

ZUFFI, Griselda. Tejiendo y destejiendo los hilos de la historia. Confluencia, v. 15, p. 145-147, 1999.

Recebido em 29 de abril de 2020.

Aceito em 20 de junho de 2020. 